\title{
Modeling the Spatial and Temporal Evolution of Stress during Multiworking Face Mining in Close Distance Coal Seams
}

\author{
Yong Zhang $\mathbb{D D}^{1,2}$ Jinkun Yang, ${ }^{1,2}$ Jiaxuan Zhang, ${ }^{1,2}$ Xiaoming Sun $\mathbb{D}^{1,2}$ Chen Chen, ${ }^{1,2}$ \\ Xiaoyu Zheng, ${ }^{1,2}$ and Huichen $\mathrm{Xu} \mathbb{D}^{3}$ \\ ${ }^{1}$ State Key Laboratory Geomechanics and Deep Underground Engineering, Beijing 10083, China \\ ${ }^{2}$ School of Mechanics and Civil Engineering, China University of Mining \& Technology, Beijing 10083, China \\ ${ }^{3}$ College of Mechanical and Architectural Engineering, Taishan University, Taian, Shandong 271000, China
}

Correspondence should be addressed to Xiaoming Sun; sunxiaoming@cumtb.edu.cn

Received 18 November 2019; Revised 16 September 2020; Accepted 20 June 2021; Published 15 July 2021

Academic Editor: Emilio Bastidas-Arteaga

Copyright (c) 2021 Yong Zhang et al. This is an open access article distributed under the Creative Commons Attribution License, which permits unrestricted use, distribution, and reproduction in any medium, provided the original work is properly cited.

Mining in close distance coal seams (CDCSs) is frequently associated with engineering disasters because of the complicated nature of stress distribution within CDCSs. In order to establish a layout of a roadway to minimize the occurrence of disasters associated with mining CDCS, here the spatial and temporal evolution of stress distribution during the multiworking face mining of a CDCS was explored through numerical simulation based on the engineering and geological conditions of the Nantun Coal Mine. The numerical simulation results indicate that, after the extraction of adjacent multiple working faces, the spatial distribution of stress can be characterized with areas of increased, reduced, and intact stress. The superposed stress of inclined seams that are very close to each other propagates through coal pillars in the bottom floor, and this propagation follows neither the line along the axis of the coal pillar nor the line perpendicular to the direction of the floor. It instead propagates along a line angled with the axis of the coal pillar. The roadway can be arranged in the area with reduced stress, to improve its the stability. Based on the computed spatial and temporal evolution of stress, an optimized layout of roadway was proposed. This layout features a reasonable interval between the mining roadway and a minimal proportion of increased stress areas along the mining roadway and is aligned with geological structures.

\section{Introduction}

In recent years, as China's energy demand has continued to grow, coal mining activities in the country have continued to expand [1]. As a result, mining in close distance coal seams (CDCSs) has become increasingly important in many coal districts in China, such as Yanzhou, Datong, Pingdingshan, and Huainan. CDCSs are coal seams that are in close proximity to other seams, i.e., the distances between the different coal seams are very small $[2,3]$. The mining of CDCSs has been accompanied by frequent disastrous phenomena, such as large deformation of surrounding roadways, rock bursts, and coal and gas outbursts. These phenomena are related to the multidimensional and dynamic redistribution of the stress of roadways in lower coal seams. It is therefore necessary to study the spatial and temporal evolution of stress in the roadways of CDCSs, in an effort to determine a general trend, so as to optimize their layout.

During several decades of CDCS mining, numerous researchers have investigated issues related to mining and roadway layout design [4-8]. Due to limitations in the available monitoring instruments and the engineering conditions, few investigations have focused on in situ stress distribution $[9,10]$. Recently, numerical simulations have increasingly been used to analyze the interactions of different extraction stages during CDCS mining. Wang et al. studied the mining interactions and reasonable positions between upper and lower mining faces using the discrete element simulation method [11]. Zhang et al. analyzed the distribution of coal pillar support pressure in the floor of a mine, using finite element numerical 
simulation. They developed a method to determine the reasonable position of the roadway for ultraclose lower seams [12]. Liu et al. studied the deformation and stress redistribution of overlying coal seams above a doubleseam extraction, using a distinct element method based on a scaled modeling experiment [13]. Guo et al. performed a numerical investigation using a three-dimensional (3D) finite element code. They used this approach to analyze the complex dynamic interaction between mining-induced strata stress changes and fractures in multiseam long wall mining at a Chinese colliery [14]. Suchowerska et al. developed a finite element model in conjunction with Wilson's equations to evaluate vertical stresses in the underlying strata. They found that the abutment angle has a significantly greater effect on the magnitude of relative changes in vertical stress in the strata below a pillar than the overburden depth [15]. Adhikary et al. presented the results of a numerical simulation of the surface subsidence induced by multiseam longwall mining, obtained using both two-dimensional (2D) and 3D versions of a Cosserat continuum-based, finite element code called COSFLOW. Their results highlighted deficiencies in 2D simulations. Other modeling studies have also focused on the stress evolution related to CSCD mining [16]. Zhu et al. studied the influence of vertical stress distribution to pillar stability during the extraction of a lower coal seam, using a 3D finite element model [17]. Zhang et al. utilized borehole imaging technology and a 2D numerical model to analyze the fissure evolution and distribution characteristics of both coal and rock, following the extraction of a lower coal seam [18]. Zhang et al. developed a 3D extraction model to explore the evolution of stresses and the effects of stress concentration and rock failure, during the extraction of an upper coal seam [19].

These studies have mainly focused on stress evolution surrounding a single working face during CSCD mining. However, stress distribution has not yet been characterized during multiworking face CSCD mining. Based on the geological and mining conditions of Nantun Mine, a 3D numerical model was built to study stress distribution during CSCD mining. This model was used to explore the spatial and temporal evolution of stress during CSCD mining. Through the description of the geological conditions, setup of the numerical model, and analysis on the evaluation of the general trend of stress redistribution, an optimized roadway layout for the lower coal seam is presented.

\section{Geological Description}

Nantun Mine is located in center of Shandong Province, China. The mine field covers an area of $43.5 \mathrm{~km}^{2}$. The mine field is dominated by wide and gentle fold structures. The faults are relatively sparse, and the secondary folds are relatively developed. It is a medium-to-simple type; the faults are mainly normal faults with a small number of reverse faults. After 40 years of mining, the main working faces have become arranged using the descending mining method in coal seams no. $3_{u}$ and no. $3_{b}$, at depths from $470 \mathrm{~m}$ to $590 \mathrm{~m}$. As shown in Figure 1, the distance between coal seam no. $3_{u}$ and no. $3_{l}$ is less than $6 \mathrm{~m}$, with a minimum of only $0.72 \mathrm{~m}$, and coal seam no. $3_{l}$ is located below coal seam no. $3_{u}$. The strata between coal seams no. $3_{U}$ and no. $3_{L}$ consist of sandstone. The thickness of coal seam no. $3_{u}$ varies from 1.4 to $5.7 \mathrm{~m}$; its average thickness is $5.05 \mathrm{~m}$. Coal seam no. $3_{l}$ is slightly thinner, ranging in thickness from 2.6 to $3.1 \mathrm{~m}$; its average thickness is $2.98 \mathrm{~m}$. The dip angles of these coal seams range from $6^{\circ}$ to $20^{\circ}$; the average dip angle is $13^{\circ}$. The site engineering geological survey shows that the horizontal tectonic stress is small. In this study, the effects of gravity stress are considered according to the buried depth; they were calculated to be $\sim 11.75-14.75 \mathrm{MPa}$.

Four working faces were arranged in the research area, which is located in the east of the 9th Panel. Figure 2 shows a schematic diagram of the working faces' layout. The weathering and oxidation of coal seam no. $3_{u}$ meant that working face $93_{l} 07$ was mined first and was finished in 2003. Mining of the other two working faces in coal seam no. $3_{u}, 93_{u} 05$ and $93_{u} 03$ was finished in 2006 and 2008, respectively.

\section{Numerical Model}

It is important to understand the stress distribution of the coal-rock mass around the working face of $93_{u} 05$ after the extraction of adjacent multiworking face and to provide guidelines for the extraction roadway arrangement and supporting method of selection for the $93_{u} 05$ working face. Here, therefore, a 3D model was developed based on the engineering geological conditions of the site, using FLAC3D. The mesh used in the model is shown in Figure 3. The method of solution in FLAC3D is characterized by the following three approaches:

(1) Finite difference approach (first-order space and time derivatives of a variable are approximated by finite differences, assuming linear variations of the variable over finite space and time intervals, respectively)

(2) Discrete-model approach (the continuous medium is replaced by a discrete equivalent-one in which all forces involved and concentrated at the nodes of a three-dimensional mesh used in the medium representation)

(3) Dynamic-solution approach (the inertial terms in the equations of motion are used as numerical means to reach the equilibrium state of the system under consideration)

The laws of motion for the continuum are, by means of these approaches, transformed into discrete forms of Newton's law at the nodes. The resulting system of ordinary differential equations is then solved numerically using an explicit finite difference approach in time.

The maximum horizontal stress of the model is $\sigma_{H}=26.5 \mathrm{MPa}$, the minimum horizontal stress of the model is $\sigma_{h}=15.0 \mathrm{MPa}$, and the vertical stress of the model is $\sigma_{V}=17.5 \mathrm{MPa}$. Boundary conditions and initial conditions are shown in Table 1. 


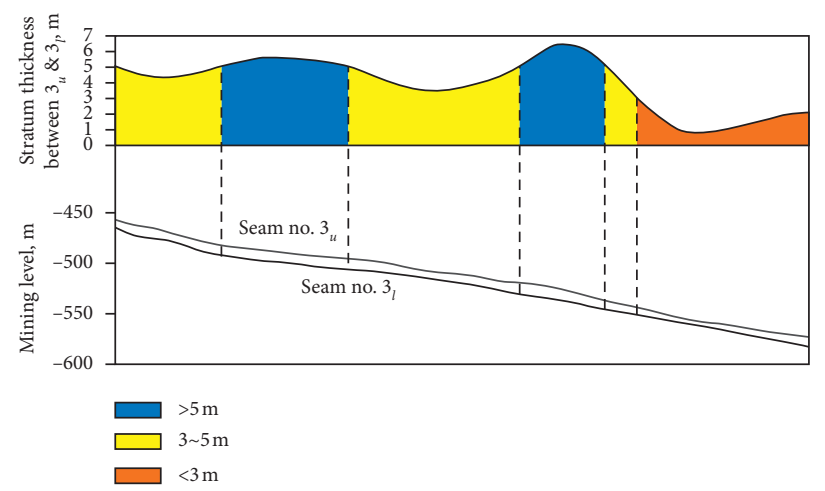

Figure 1: The vertical section and variation in stratum thickness between coal seams no. $3_{u}$ and no. $3_{l}$.

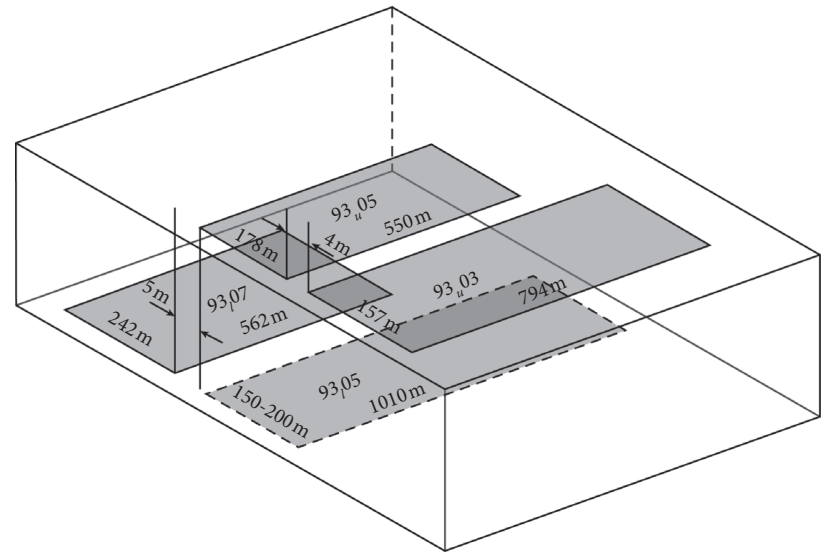

(a)

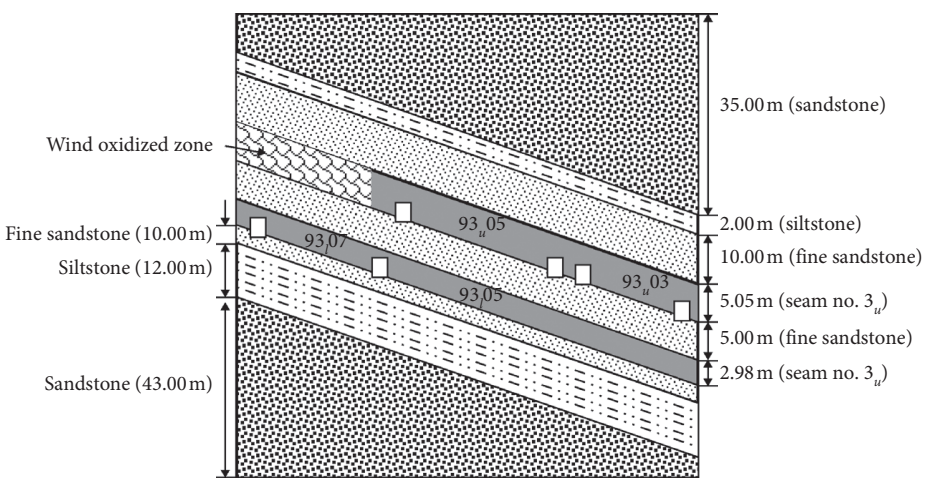

(b)

FIGURE 2: Working face layout of no. $3_{u}$ and no. $3_{l}$ coal seams: (a) 3D view of the spatial location of working faces and (b) cross-sectional view of the working face.

The model included the working faces of $93_{l} 07,93_{u} 05$, and $93_{u} 03$. All of the working faces have significant impacts on the internal stress distribution of the no. $3_{l}$ coal seam. The simulation's domain is $700 \mathrm{~m} \times 300 \mathrm{~m} \times 300 \mathrm{~m}$, and it is divided into 411286 elements and 437511 nodes. The numerical simulation focuses on $60 \mathrm{~m}$ of each side along the directions of the $93_{l} 07$ and $93_{u} 03$ working faces, which are close to the $93_{u} 05$ working face.

An initial stress field is imposed by the self-weight of the rock mass. Zero normal displacements are prescribed on the lateral boundaries of the model. Vertical displacements are prevented at the bottom. A stress of $10 \mathrm{MPa}$ is fixed at the top of the model's domain according to the depth of the top surface.

Material damage is calculated according to the Mohr-Coulomb strength criterion. The physical and mechanical parameters are listed in Table 2. Based on the experimental results of USBM (United States Bureau of Mines), the Salamon model was used to simulate the rock mass of the goaf $[20,21]$.

In order to clearly delineate the impact of each working face to the mining stress distribution of the $93_{l} 05$ working 


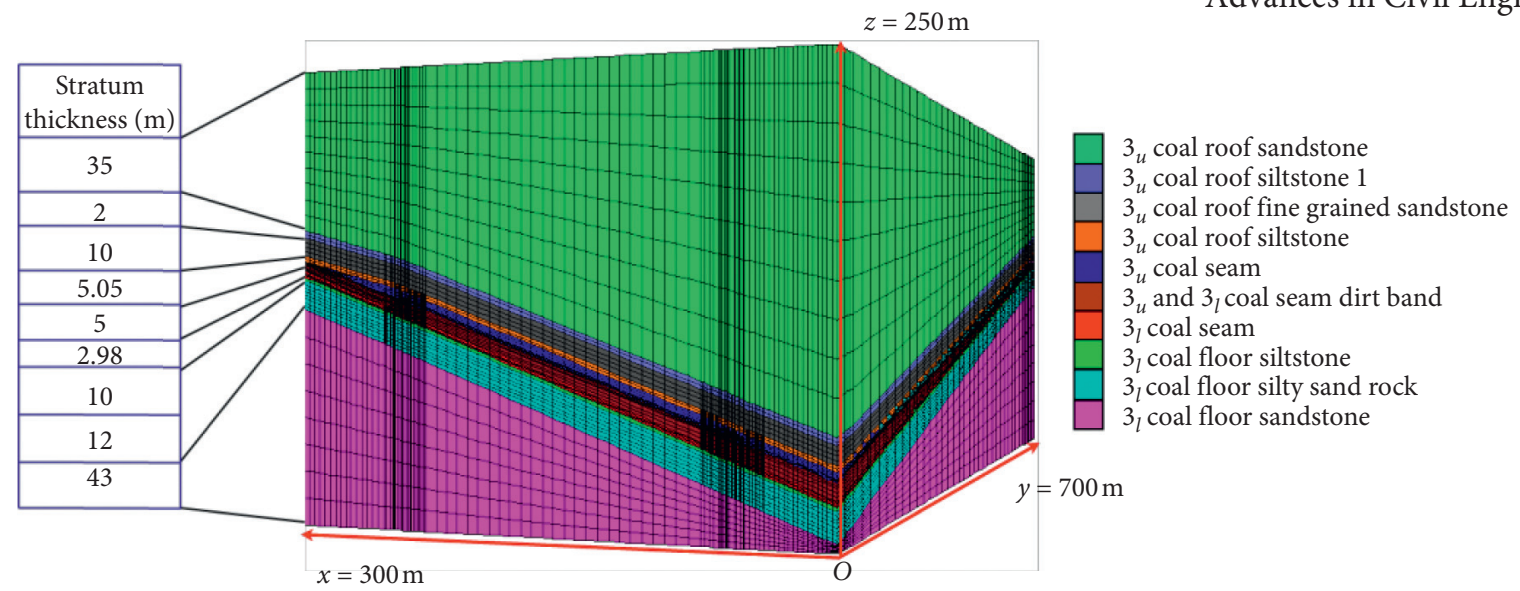

FIGURE 3: Engineering geological model.

TABLE 1: Boundary conditions and initial conditions.

\begin{tabular}{|c|c|c|c|c|}
\hline Boundary conditions & Displacement boundary & Stress boundary $(\mathrm{MPa})$ & Initial stress conditions & Value (MPa) \\
\hline Left and right boundary conditions & 0 & & $\sigma_{H}$ & 26.5 \\
\hline Front and back boundary conditions & 0 & & $\sigma_{h}$ & 15.0 \\
\hline Bottom boundary condition & 0 & & $\sigma_{V}$ & 17.5 \\
\hline Top boundary condition & & 10 & & \\
\hline
\end{tabular}

TABLe 2: Physical and mechanical parameters of different engineering rockmass.

\begin{tabular}{|c|c|c|c|c|c|c|}
\hline Lithology name & $\begin{array}{c}\text { Unit weight } \\
\left(\mathrm{kg} / \mathrm{m}^{3}\right)\end{array}$ & $\begin{array}{c}\text { Bulk modulus } \\
(\mathrm{GPa})\end{array}$ & $\begin{array}{l}\text { Shear modulus } \\
(\mathrm{GPa})\end{array}$ & $\begin{array}{c}\text { Tensile strength } \\
(\mathrm{MPa})\end{array}$ & $\begin{array}{l}\text { Bond force } \\
(\mathrm{MPa})\end{array}$ & $\begin{array}{c}\text { Internal friction } \\
\text { angle }\left({ }^{\circ}\right)\end{array}$ \\
\hline $3_{u}$ coal seam & 1360 & 2.1 & 1.5 & 0.8 & 2.5 & 28 \\
\hline $\begin{array}{l}3_{u} \text { coal roof fine grained } \\
\text { sandstone }\end{array}$ & 2650 & 8.6 & 6.9 & 3.1 & 5.8 & 37 \\
\hline $3_{l}$ coal floor silty sand rock & 2670 & 8.1 & 4.2 & 2.0 & 6.4 & 35 \\
\hline $3_{l}$ coal floor sandstone & 2690 & 8.2 & 6.4 & 3.2 & 6.0 & 39 \\
\hline $\begin{array}{l}3_{u} \text { and } 3_{l} \text { coal seam dirt } \\
\text { band }\end{array}$ & 2620 & 4.0 & 2.5 & 1.0 & 3.2 & 32 \\
\hline $3_{u}$ coal roof sandstone & 2680 & 9.0 & 7.6 & 4.0 & 6.0 & 40 \\
\hline $3_{u}$ coal roof siltstone & 2780 & 8.2 & 4.0 & 3.1 & 6.2 & 38 \\
\hline $3_{l}$ coal floor siltstone & 2600 & 7.5 & 4.5 & 2.0 & 4.2 & 31 \\
\hline $3_{u}$ coal roof siltstone 1 & 2780 & 8.2 & 5.0 & 3.1 & 6.2 & 36 \\
\hline 3, coal seam & 1320 & 2.0 & 1.3 & 0.8 & 2.0 & 28 \\
\hline
\end{tabular}

face and considering the oblique angle between the stopmining line and the roadway of $93_{u} 05$ working face, a simulation sequence composed of four steps was used (Figure 4) as follows:

(1) The extraction of the $93_{l} 07$ working face

(2) The $200 \mathrm{~m}$ extraction of the $93_{u} 05$ working face

(3) The extraction of the $93_{u} 05$ working face

(4) The extraction of the $93_{u} 03$ working face

According to the actual mining sequence of the working face in the calculation model, firstly mine the $93_{l} 07$ working face, then combine the actual layout of the $93_{u} 05$ working face stop line to mine $200 \mathrm{~m}$ first, then mine the $93_{u} 05$ remaining working face, and finally mine $93_{u} 03$ working surface.

\section{Model Results and Discussion}

4.1. Spatial and Temporal Evolution of Mine Stress. According to the research results of Suchowerska et al. [15] and Zhang [22], the factor that has the greatest influence on the stress distribution of the lower coal during multi-coal mining is the safe coal column left after the upper coal is mined, mainly manifested as the significant change in vertical stress, and with the change of the inclination of the coal seam, the stress distribution in the lower coal will be more complicated. Therefore, based on the abovementioned research results, this paper focuses on the stress distribution in the next coal seam after the vertical stress and the lateral stress are superimposed when the coal seam is mined at a close distance. 


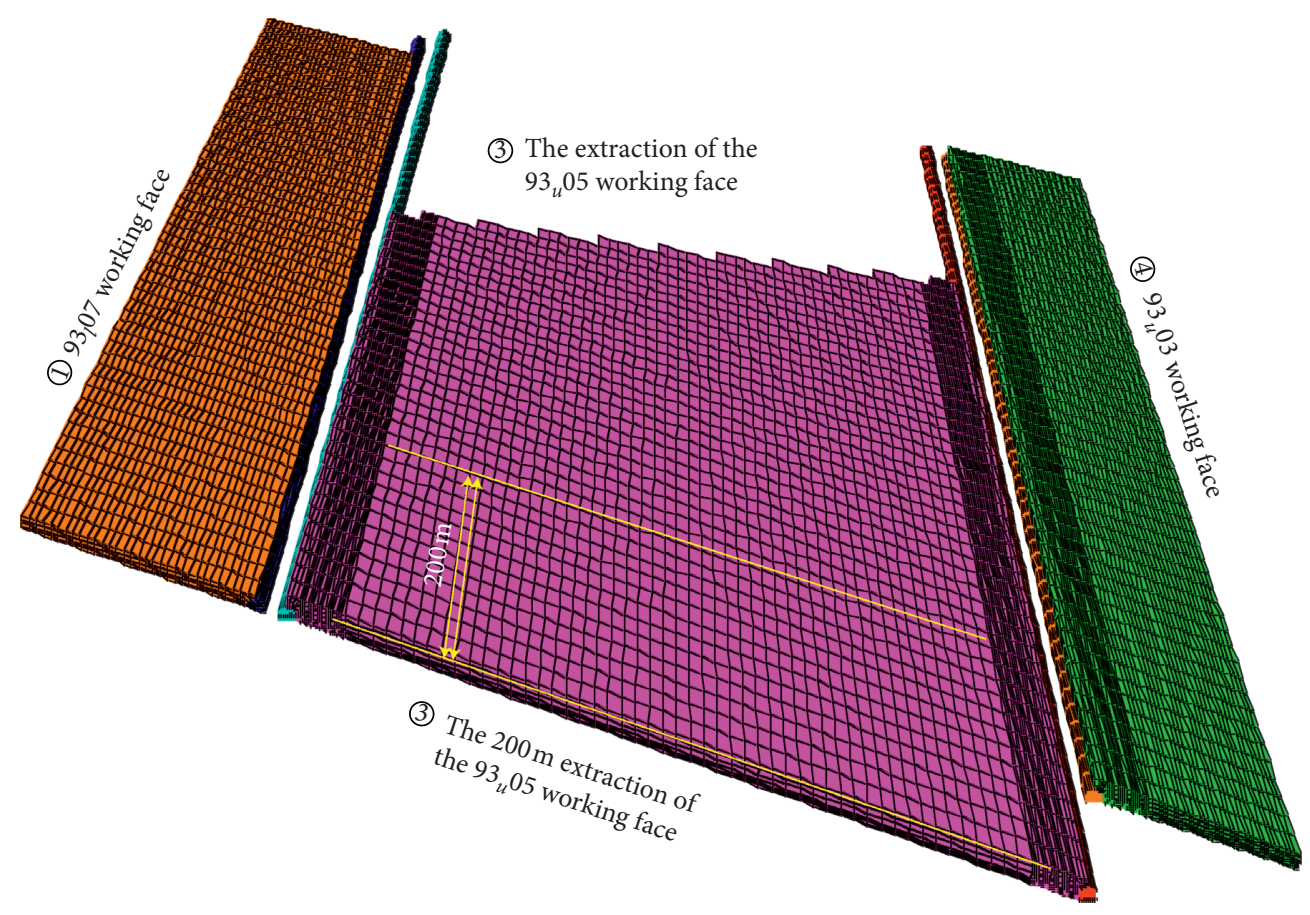

FIGURE 4: Schematic diagram of the simulation sequence.

Figure 5 shows the vertical stress distribution of the lateral bearing pressure of the $93_{d} 05$ working face at each step. In Figure 5, the $X$ and $Y$ coordinates represent the transverse and longitudinal directions of the horizontal plane of the no. $3_{l}$ coal seam, respectively, and the $Z$ coordinate corresponds to the vertical direction of the no. $3_{l}$ coal seam.

Figure 5(a) shows the mine's stress distribution after the extraction of the $93_{l} 07$ working face (Step 1). The distribution of vertical stress in the no. $3_{l}$ coal seam after the extraction of the $93_{l} 07$ working face is similar to what is typically observed after the extraction of a single coal seam [23-25]. It exhibits the following features:

(1) A zone affected by abutment pressure appears around the mining area after the extraction of the 93,07 working face. This zone can be divided into a subzone affected by the advanced abutment stress and a subzone affected by the lateral abutment stress.

(2) The zone affected by the lateral abutment stress is located within the 93,05 working face. The horizontal distance from the edge of the $93_{l} 07$ goaf to area of maximum lateral abutment stress $(38 \mathrm{MPa})$ is $9.5 \mathrm{~m}$. Considering an original rock stress of 13.5 $\mathrm{MPa}$, the apparent stress concentration has a factor of 2.8 .

Figure 5(b) shows the stress distribution after mining $200 \mathrm{~m}$ along the $93_{u} 05$ working face (Step 2). As this process is modelled, the abutment stress affects an area around the goaf of the underlying coal seam. The vertical stresses of the $93_{u} 05$ and $93_{l} 07$ working faces are superposed onto each other. The area of maximum stress $(68 \mathrm{MPa})$ is located where the advanced abutment pressure of the $93_{u} 05$ face overlaps the lateral abutment stress of the $93_{l} 07$ working face; it is located $9 \mathrm{~m}$ in front of the $93_{u} 05$ working face.

Step 3 concerns the extraction of the $93_{u} 05$ working face. Here, the lateral abutment stress of the $93_{u} 05$ working face increases because the suspension area of the main roof of the $93_{l} 07$ working face expands (Figure 5(c)). The peak values of vertical stress between the $93_{u} 05$ and $93_{d} 07$ working faces both also increase, reaching $75 \mathrm{MPa}$ (with a stress concentration factor of 4.3). In the area of the $93_{l} 07$ goaf, the stress at the edge of goaf is relatively low. Here, the vertical stress increases due to the expansion of mining area, which leads to a continuous compaction of the internal rock, thereby increasing its strength. The stress transmits from the upper strata of rock to the bottom, and parts of the area recover to their original rock stress.

Figure 5(d) shows the stress distribution after the extraction of the $93_{u} 03$ working face in Step 4 . The following observations can be made:

(1) The vertical stress field in the no. $3_{l}$ coal seam can be divided into three zones: a zone with increased stress, a zone with reduced stress, and a zone with intact rock stress. The zone with increased stress includes zones with superposition of stress and without superposition of stress (i.e., a single working face).

(2) The vertical stress increases in each working face in the area around the no. $3_{l}$ coal seam. This is manifested in two kinds of zones with stress superposition: zones with superposed lateral abutment stress between two working faces and zones where the advanced abutment stress of a given working face superposes with the lateral abutment stress of the other working face. The latter type of zone has larger 


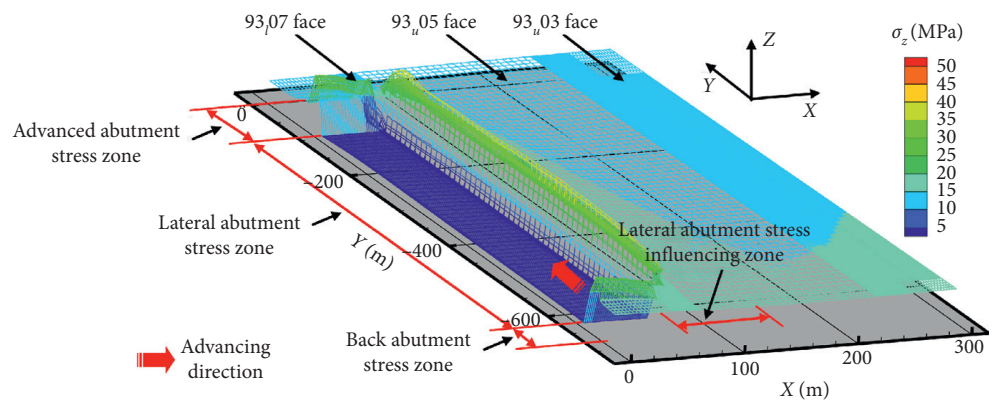

(a)

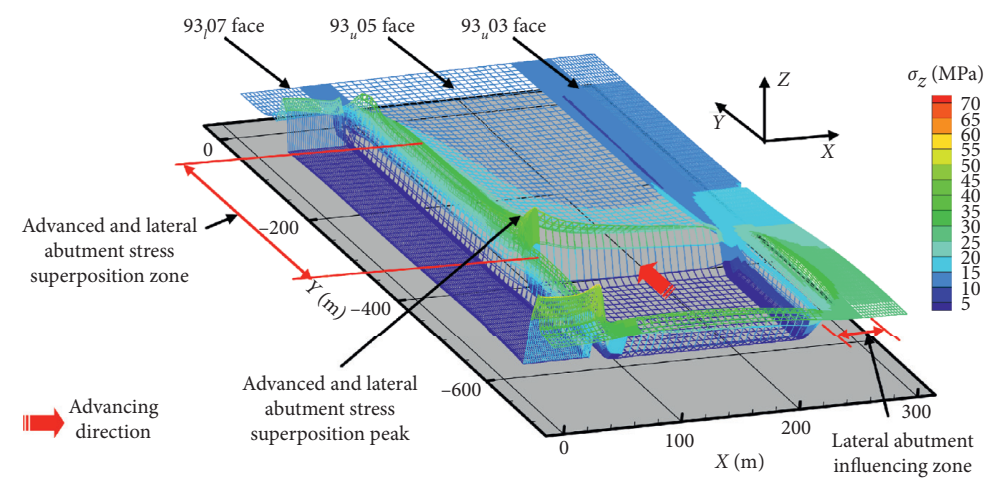

(b)

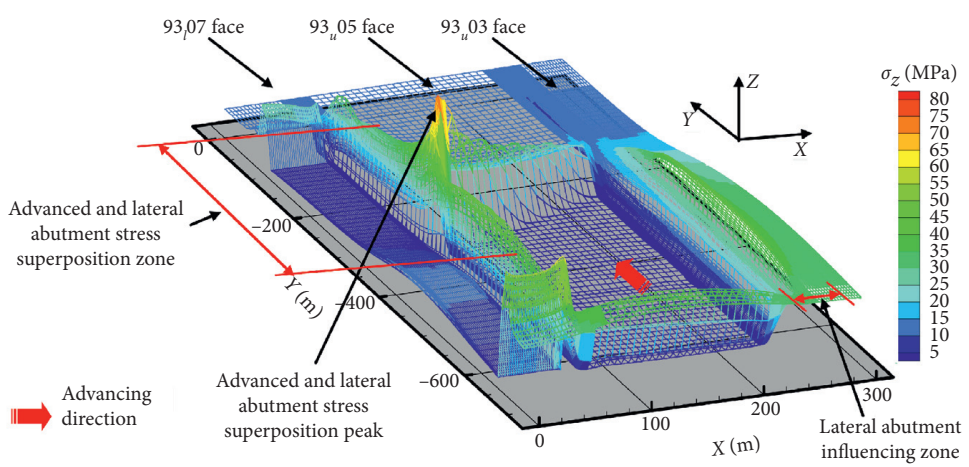

(c)

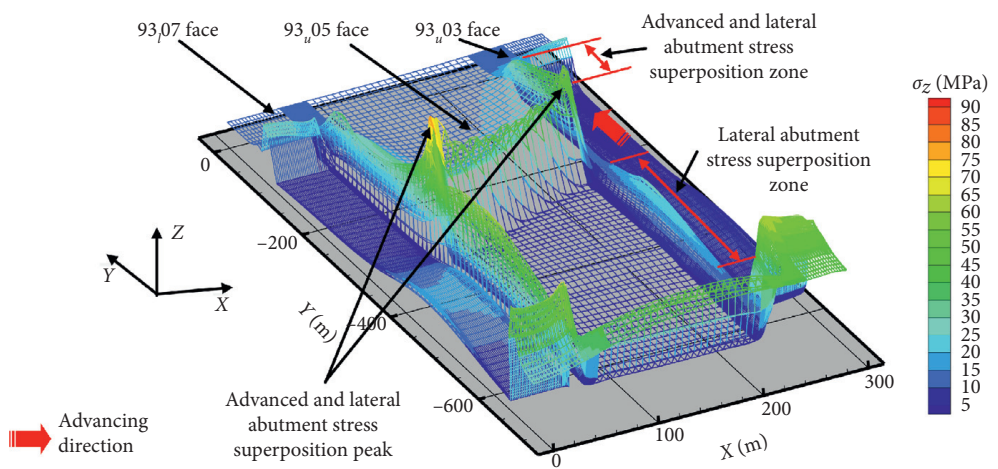

(d)

Figure 5: Vertical stress distribution of the coal-rock mass in the no. $3_{l}$ coal seam (a) after extraction of the $93_{l} 07$ working face; (b) after a $200 \mathrm{~m}$ extraction of the $93_{u} 05$ working face; (c) after extraction of the $93_{u} 05$ working face; (d) after extraction of the $93_{u} 03$ working face. 
peak stress and subsequently has a more significant influence on the no. $3_{l}$ coal seam.

(3) Though there are zones with raised stress, there are also zones with reduced vertical stresses, such as the unloading area of the excavation of mining roadway and the edge of the goaf. The mining roadway is arranged along the area with reduced stress so that the negative influence of vertical stress on the stability of the roadway is diminished.

(4) As shown in Figure 5(d), because the $93_{l} 07$ working face is located in the no. $3_{l}$ coal seam, the stress caused by the superposition of the abutment stress of the 93,07 working face and the abutment stress of the $93_{u} 05$ working face is very high. As a result, if the upper mining roadway of the $93_{l} 05$ working face is arranged as a gob-side entry, both its location and the supporting method used should be chosen carefully.

4.2. Vertical Stress Superposition. Regarding the extraction of a multiworking face of a CDCS, the stress at the stopes of the surrounding rock mass evolves dynamically and superposes with each other. Figure 6 illustrates the vertical stress distribution curves at $Y=-500 \mathrm{~m},-320 \mathrm{~m},-285 \mathrm{~m}$, and $-150 \mathrm{~m}$. Regarding the vertical stress superposition, the following observations can be made:

(1) In the middle of the $93_{u} 05$ working face $(Y=-500 \mathrm{~m})$, the vertical stresses caused by the extraction of the $93_{l} 07$ and $93_{u} 05$ working faces superpose each other. This stress is transmitted to the no. $3_{l}$ coal seam through a narrow coal-rock mass between the two working faces, which creates a zone of maximum stress in the no. $3_{l}$ coal seam. The vertical stresses caused by the extraction of the $93_{u} 05$ and $93_{u} 03$ working faces also superpose each other and are transmitted to the coal floor through the section coal pillar. This creates another area of maximum stress in the no. $3_{l}$ coal seam. The length of the section coal pillar between the two working faces is $4 \mathrm{~m}$.

(2) In front of the stop line of the $93_{u} 05$ working face $(Y=-320 \mathrm{~m},-285 \mathrm{~m})$, the abutment stress caused by the extraction of the $93_{u} 05$ working face superposes the lateral abutment pressure caused by the extraction of the $93_{l} 07$ and $93_{u} 03$ working faces adjacent to the mining roadway. The superposed stress propagates to the no. $3_{l}$ coal seam via the no. $3_{u}$ coal floor, and an area of peak stress forms in the no. $3_{l}$ coal seam.

(3) In the $93_{u} 05$ working face far from stop line $(Y=-150 \mathrm{~m})$, the abutment pressures caused by the extraction of the $93_{u} 05,93_{l} 07$, and $93_{u} 03$ working faces superpose each other. The peak vertical stress is low because the advanced abutment pressure of the $93_{u} 05$ working face is low.

(4) The superposed lateral abutment pressure caused by the $93_{u} 03$ and $93_{u} 05$ working faces is lower than that

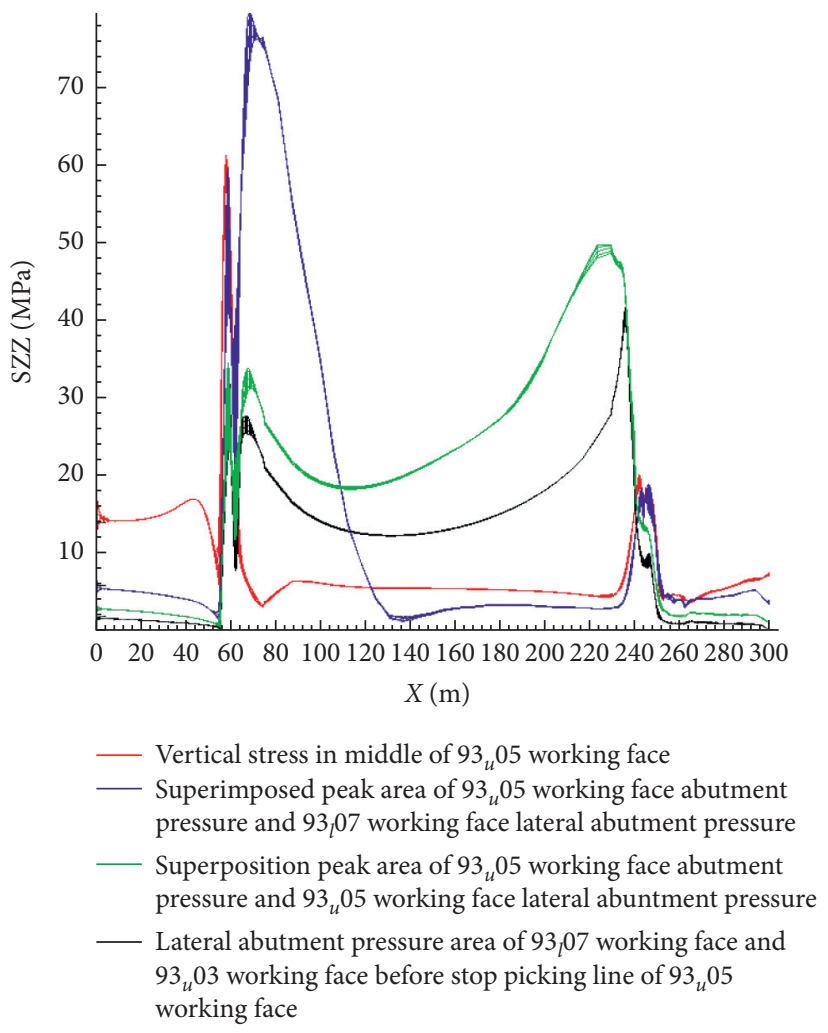

FIGURE 6: Vertical stress distribution curve for $Y=-500 \mathrm{~m},-320 \mathrm{~m}$, $-285 \mathrm{~m}$, and $-150 \mathrm{~m}$. SZZ denotes vertical stress.

caused by the $93_{u} 05$ and $93_{l} 07$ working faces because the coal pillar between the $93_{u} 03$ and $93_{u} 05$ working face is small and the lateral abutment stress in the $93_{l} 07$ and $93_{u} 05$ working faces in the two coal seams has already been sufficiently superposed.

(5) Figure 7 shows that the superposed stress of the inclined seams is transmitted through the coal pillars in the bottom floor. This transmission path follows neither the line along the axis of the coal pillar, nor the line perpendicular to the direction of the floor, but instead follows along a line aligned with the axis of the coal pillar.

4.3. Optimization of the Roadway Layout. After the coal seam is mined, affected by the redistribution of the mining stress field, the floor surrounding rock presents three different states: active limit zone, transition zone, and passive limit zone $[26,27]$. Taking the horizontal coal seam as an example, its distribution is shown in Figure 8.

$$
h_{\max }=\frac{L \times \sin \theta}{2 \cos ((\pi / 4)+(\varphi / 2))} \times e^{((\pi / 4)+(\varphi / 2)) \times \tan \varphi},
$$

Combining with the measured data in Nantun Coal Mine, firstly, the vformula [9] is used to calculate the depth of the floor fracture zone under horizontal conditions to be $7.6 \mathrm{~m}$, which is greater than the thickness of the gangue between the two layers of coal.where $L$ is the distance between the maximum support stress and the working surface 


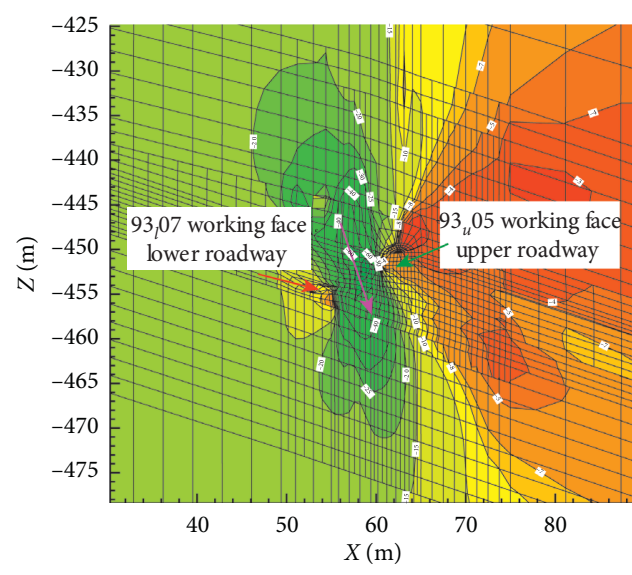

(a)

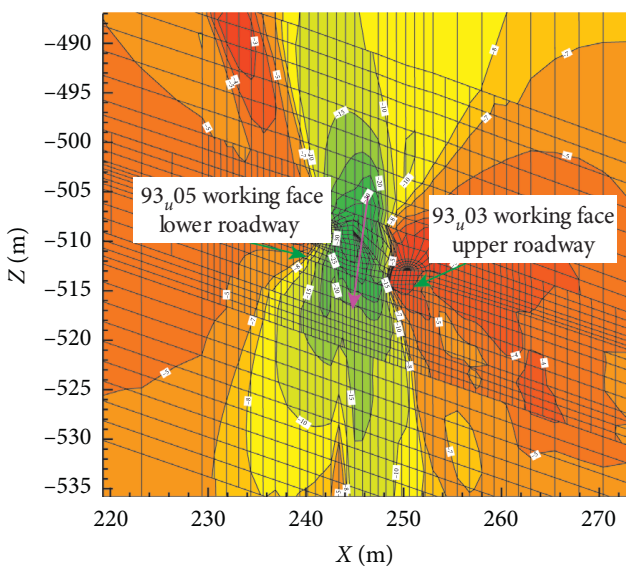

(b)

Figure 7: The vertical stress direction near the mining roadway in the $93_{u} 05$ working face $(Y=-500 \mathrm{~m})$.

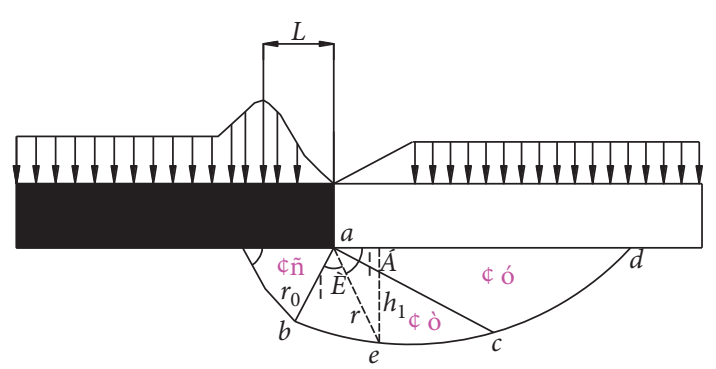

FIGURE 8: Sectional view of plastic failure zone of bottom floor.

and $\varphi$ is the internal friction angle between the two coal seams.

Secondly, analyze the approximate distribution of the failure area of the surrounding rock of the floor, taking the inclination of the coal seam into consideration, as shown in Figure 9.

Affected by the mining of the upper 3 coal seams and the 9307 working face, the damage depth of the surrounding rock at the lower mining roadway floor of the $93_{l} 05$ working face is greater than that of the upper mining roadway floor of the $93_{l} 05$ working face. Therefore, when the working face is laid out, the distance between the two mining roadway $s$ and the remaining coal columns of the upper layer should be arranged differently.

This section details an optimized roadway layout according to the computed spatial and temporal evolution of stress, especially the vertical stress curve shown in Figure 7. Due to the mining of the $93_{l} 07$ working face and considering that the left side mining roadway of the $93_{l} 05$ working face can avoid the stress concentration area formed by the upper coal columns in the lower coal, the left side mining roadway of the $93_{l} 05$ working face can only be arranged under the goaf of the $93 u 05$ working face and staggered a certain safe distance from the coal column in the spatial position; combined with the analysis of Figure 7, it can be seen that the stress concentration in the coal seam in this area is affected by the mining of the two working faces of the 3 upper coal seam. It tends to develop obliquely to the lower left.

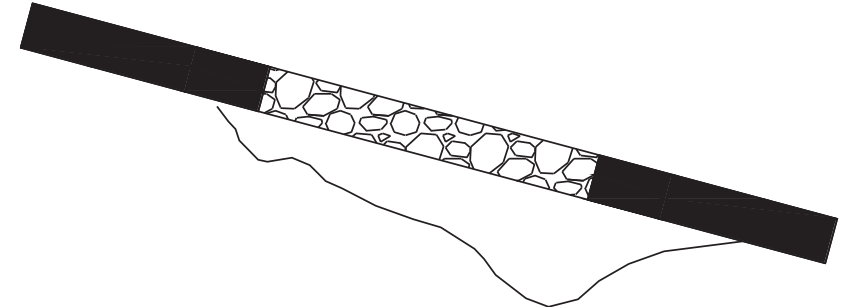

FIGURE 9: Distribution of the failure area of the surrounding rock of the floor with inclination.

Therefore, when arranging the right side mining roadway under $93_{l} 05$, it should be spaced apart from the coal columns left by the upper coal. Comprehensive analysis shows that the best two of mining roadway $s$ in the 93,05 working face should adopt the interior staggering type (note: the lower working face is drawn along the groove internal staggering layout).

Eventually, an arrangement for the mining roadway of the 93,05 working face is determined, which is shown in Figure 10. The upper mining roadway of the $93_{l} 05$ working face is located in the lower stress zone of the $93_{u} 05$ working face goaf. The distance between the top of the upper mining roadway of the 93,05 working face and the bottom of the mining roadway of the $93_{l} 07$ working face is $6 \mathrm{~m}$. The lower mining roadway of the $93_{1} 05$ working face is located in the lower stress zone of the $93_{u} 05$ working face goaf. The distance between the low side of the mining roadway of the $93_{l} 05$ working face and the low side of the mining roadway of the $93_{u} 05$ working face is $9 \mathrm{~m}$.

\subsection{Analysis of the Engineering Effect after Optimization of the} Roadway Layout. Two survey stations are set up to monitor the surface displacement of tunnel along the gob-side entry during the excavation. This allows for the layout optimization effect of the roadway to be examined. The location of each station is shown in Figure 11.

According to the results presented in Figures 12 and 13, the rock deformation surrounding the roadway obeys the 


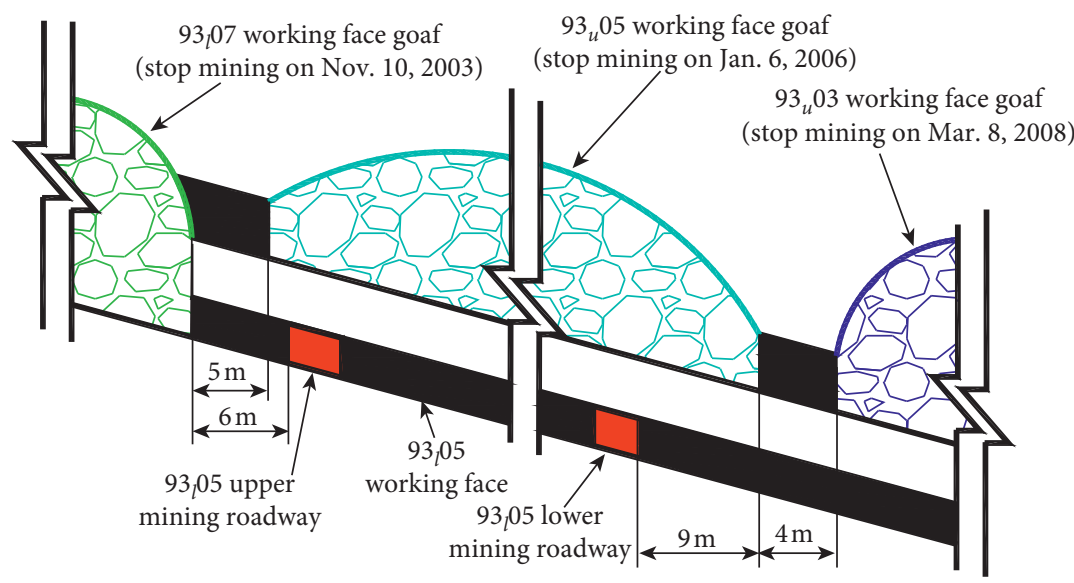

FIGURE 10: Schematic showing the modelled upper and lower mining roadways in the $93_{l} 05$ working face.

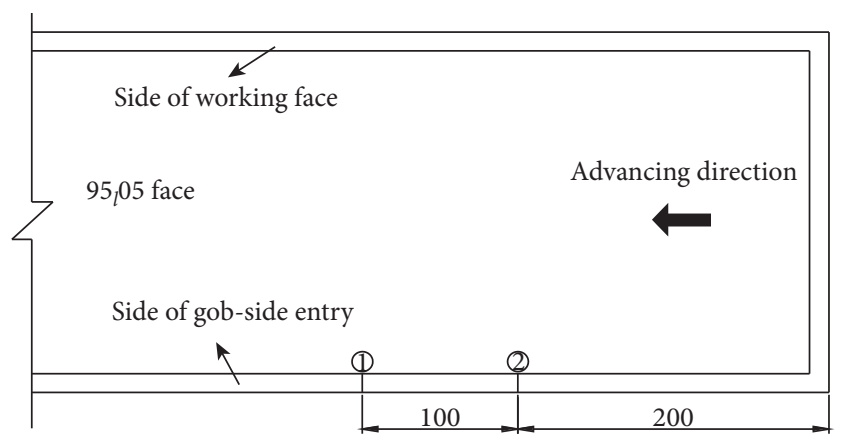

FiguRE 11: Location sketch map of the survey stations.

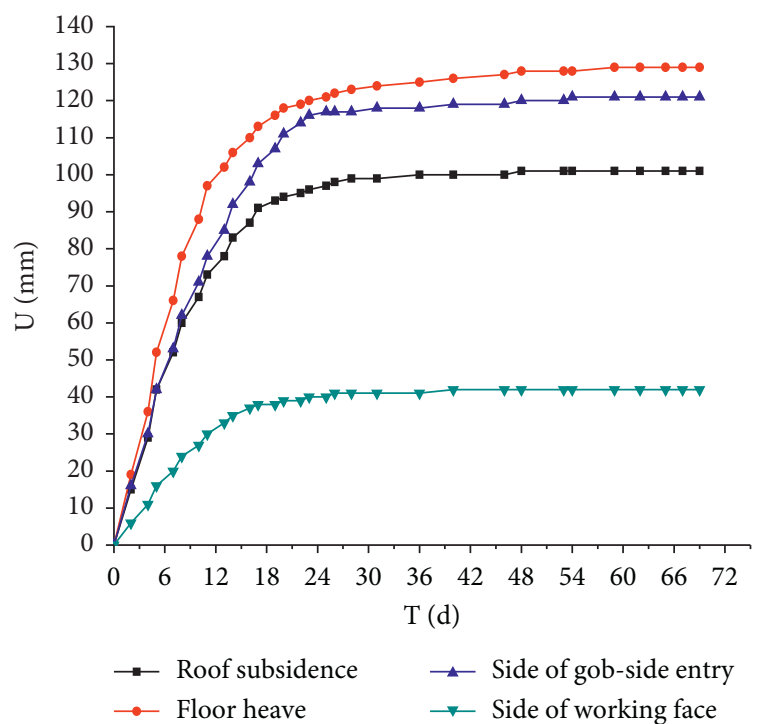

FIGURE 12: Relationship curves of surface displacement versus time for the No.1 survey station, during the excavation time.

following rule: during the excavation, the extent of roof subsidence in the tunnel along the goaf is $101 \mathrm{~mm}$, the largest floor heave is $129 \mathrm{~mm}$, and the largest extent of convergence on both sides of the tunnel is $163 \mathrm{~mm}$. The changes in surface displacement over time monitored by stations 1 and 2

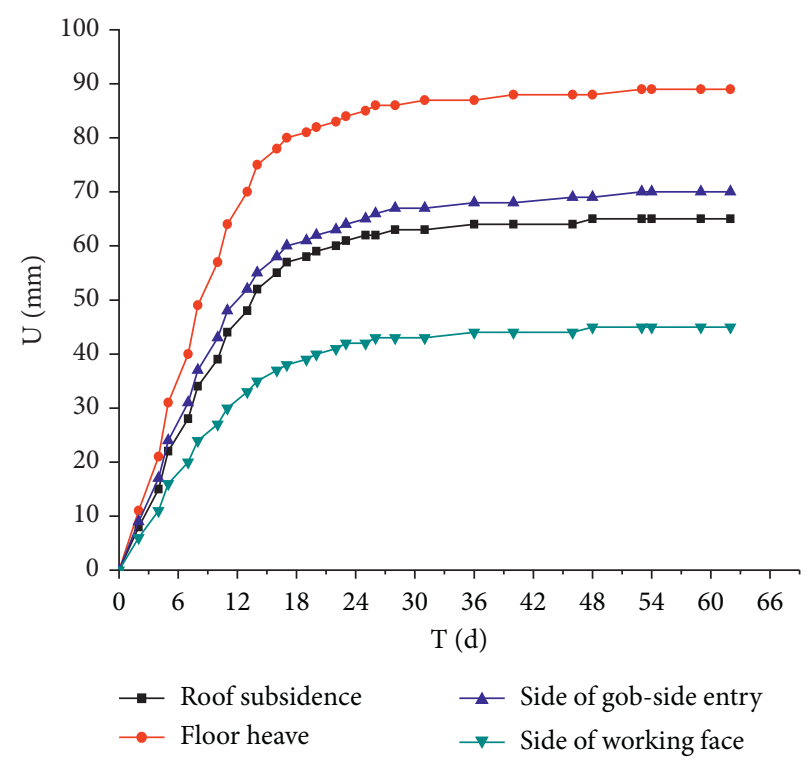

FIGURE 13: Relationship curves of surface displacement versus time for the No. 2 survey station, during the excavation time.

during the excavation are displayed in Figures 10 and 11. The results show that the optimization of the layout of the roadway, to enable stability control for the Nantun coal mine, is feasible.

\section{Conclusion}

CDCS has been accompanied by frequent disastrous phenomena, which are related to the multidimensional and dynamic redistribution of the stress of the roadway in lower coal seams. It is therefore necessary to study the spatial and temporal evolution of stress in these roadways and to optimize their layout so as to minimize the risks associated with CDCS mining. In this paper, based on analysis of the engineering and geological conditions of the Nantun Mine, China, a numerical model was developed to study the superposition and dynamic evolution of stress when multiple working faces were successively extracted. The model's results regarding the spatial and temporal evolution of mining 
stress distribution during the extraction of the working face of the underlying coal seam were presented and analyzed.

These results show that there are areas with increased, reduced, and intact stress near the stope, after the extraction of the adjacent multiple working faces of a CDCS. The areas with increased stress include the mining stress zone of a single working face and superposed stress zone. The areas with reduced stress exist within the mining roadways and at the edge of the goaf. The mining roadway can therefore be arranged in the area with reduced stress to improve the stability of roadway. The stress superposition of inclined seams that are very close to each other propagates through coal pillars in the bottom floor, and the propagation path follows neither the line along the axis of the coal pillar, nor the line perpendicular to direction of the floor. This path instead follows a line aligned with the axis of the coal pillar.

Finally, based on the computed spatial and temporal evolution of stress, especially the vertical stress distribution, an optimized layout of roadway was proposed. This layout features a reasonable interval between the mining roadway and a minimal proportion of increased stress areas along the mining roadway and is aligned with geological structures.

\section{Data Availability}

The data used to support the findings of this study are included within the article.

\section{Conflicts of Interest}

The authors declare that there are no conflicts of interest regarding the publication of this paper.

\section{Acknowledgments}

This work was supported by the National Natural Science Foundation of China Youth Fund (Grant no. 51904306), the National Key Research and Development Plan of China (Grant no. 2016YFC0600901), the State Key Laboratory of Open Funds (Grant no. SKLGDUEK1826), the National Natural Science Foundation of China (Grant no. 51874311), the Special Fund of Basic Research and Operating (Grant no. 2009QL03), and the Yueqi Outstanding Scholar Award Program of China University of Mining and Technology, Beijing.

\section{References}

[1] W. J. Yu, B. Pan, F. Zhang, S. Yao, and F. Liu, "Deformation characteristics and determination of optimum supporting time of alteration rock mass in deep mine," KSCE Journal of Civil Engineering, vol. 23, no. 11, pp. 4921-4932, 2019.

[2] H. Yan, J. X. Zhang, B. Li, and C. Zhu, "Crack propagation patterns and factors controlling complex crack network formation in coal bodies during tri-axial supercritical carbon dioxide fracturing-ScienceDirect," Fuel, vol. 286, Article ID 119381, 2021.

[3] Y. L. Tan, T. B. Zhao, and Y. X. Xiao, "In situ investigations of failure zone of floor strata in mining close distance coal seams," International Journal of Rock Mechanics and Mining Sciences, vol. 47, pp. 865-870, 2010.
[4] S. S. Peng and U. Chandra, "Getting the most from multipleseam reserves," Coal Mining and Processing, vol. 18, no. 5, pp. 78-84, 1980.

[5] S. M. Hsiung and S. S. Peng, "Design guidelines for multipleseam mining," Coal Mining, Part I.vol. 9, pp. 42-60, 1987.

[6] S. M. Hsiung and S. S. Peng, "Design guidelines for multipleseam mining," Coal Mining, Part II, vol. 24, no. 10, pp. 48-50, 1987.

[7] Y. W. Shi, Surrounding Rock Stress Analysis and Optimal Design for Multi-Seam Coal Mine, Coal Mining, Beijing, China, 1995.

[8] J. L. Ellenberger, F. E. Chase, and C. Mark, "Using site case histories of multiple seam coal mining to advance mine design," in Proceedings of the 22nd International Conference on Ground Control in Mining, pp. 59-64, Morgantown, WV, USA, 2003.

[9] W. Chou, "The characteristics of ground pressure of roadway in closed coal seam," Chinese Journal of Rock Mechanics and Engineering, vol. 2, p. 173, 1993.

[10] S. Ping and W. Li, "The behavior of ground pressure of combined mining roadways in steep inclined and closed seam group," Coal Science and Technology, vol. 10, pp. 2-6, 1994.

[11] Y. J. Wang, L. Tao, and J. Xing, "DDA simulation research for multi-effect of multi-seam," Journal of Northeast University Nature and Science, vol. 4, pp. 374-377, 1997.

[12] B. Zhang, S. Yang, L. Kang, and Y. Zhai, "Discussion on method for determining reasonable position of roadway for ultra-close multi seam," Chinese Journal of Rock Mechanics and Engineering, vol. 1, pp. 97-100, 2008.

[13] Y. K. Liu, F. B. Zhou, L. Liu, C. Liu, and S. Y. Hu, "An experimental and numerical investigation on the deformation of overlying coal seams above double-seam extraction for controlling coal mine methane emissions," International Journal of Coal Geology, vol. 87, pp. 139-149, 2011.

[14] H. Guo, L. Yuan, B. T. Shen, Q. D. Qu, and J. H. Xue, "Mininginduced strata stress changes, fractures and gas flow dynamics in multi-seam longwall mining," International Journal of Rock Mechanics and Mining Sciences, vol. 54, pp. 129-139, 2012.

[15] A. M. Suchowerska, R. S. Merifield, and J. P. Carter, "Vertical stress changes in multi-seam mining under super critical longwall panels," International Journal of Rock Mechanics and Mining Sciences, vol. 61, pp. 306-320, 2013.

[16] D. AdhikaryM. Khanal et al., "Deficiencies in 2D simulation: a comparative study of 2D versus 3D simulation of multi-seam longwall mining," Rock Mechanics and Rock Engineering, vol. 49, no. 6, pp. 2181-2185, 2015.

[17] W. B. Zhu, J. L. Xu, X. Kong, D. Y. Xuan, and W. Qin, "Study on pillar stability of Wongawilli Mining Area in shallow close distance coal seams," Progress in Earth and Planetary Sciences, vol. 1, no. 1, pp. 235-242, 2009.

[18] D. Zhang, X. Qi, G. Yin, and B. Zheng, "Coal and rock fissure evolution and distribution characteristics of multi-seam mining," International Journal of Mining Science and Technology, vol. 23, no. 6, pp. 835-840, 2013.

[19] M. Zhang, H. Shimada, T. Sasaoka, K. Matsui, and L. Dou, "Evolution and effect of the stress concentration and rock failure in the deep multi-seam coalmining," Environmental Earth Sciences, vol. 72, no. 3, pp. 629-643, 2014.

[20] G. J. Chekan and J. M. Listak, Design Practices for MultipleSeam Longwall Mines, Bureau of Mines IC 9360, Washington, DC, USA, 1993.

[21] S. S. Peng, Coal Mine Ground Control, Society for Mining, Metallurgy \& Exploration, Englewood, CO, USA, 3rd edition, 2008. 
[22] W. Zhang, D. Zhang, D. Qi, W. Hu, W. He, and W. Zhang, "Floor failure depth of upper coal seam during close coal seams mining and its novel detection method," Energy Exploration \& Exploitation, vol. 36, pp. 1265-1278, 2018.

[23] M. Qian and T. Liu, Mining Stress and its control. Coal Mining, Indian Press, Beijing, China, 1991.

[24] M. Qian and X. Miao, Key Strata Theory for Rock Strata Control, China University of Mining \& Technology Press, Xuzhou, China, 2000.

[25] S. Zhu, Z. Jian, H. Hou, W. Xiao, and P. Yao, “Analytical model and application of stress distribution on mining coal floor," Journal of China University of Mining and Technology, vol. 18, no. 1, pp. 13-17, 2008.

[26] C. Wai-Fan, Limit Analysis and Soil Plasticity, Elsevier Scientific Publishing Company, New York, NY, USA, 1975.

[27] A. H. Wilson, "An hypothesis concerning pillar stability," Mining Engineer, vol. 131, no. 6, pp. 409-417, 1982. 